\title{
Parametric Experimentation on Pantographic Unit Cells Reveals Local Extremum Configuration
}

\author{
N. Nejadsadeghi ${ }^{1} \cdot$ M. De Angelo ${ }^{2,3} \cdot$ R. Drobnicki ${ }^{4}$ T. Lekszycki ${ }^{5,6} \cdot$ F. dell'Isola ${ }^{7,8} \cdot$ A. Misra $^{3}$ (D)
}

\begin{abstract}
Pantographic metamaterials are known for their ability to have large deformation while remaining in the elastic regime. We have performed a set of experiments on 3D printed pantographic unit cells to parametrically investigate their response when undergoing tensile, compression, and shear loading with the aim of i) studying the role of each parameter in the resultant mechanical behavior of the sample, and ii) providing a benchmark for the mathematical models developed to describe pantographic structures. Results show the existence of local extrema in the space of the geometrical parameters, suggesting the use of optimization techniques to find optimal geometrical parameters resulting in desired functionalities. We have also performed tensile relaxation tests on the samples, with the results indicating the complexity of the dynamic behavior and the existence of multiple relaxation characteristic times. Such results can be used to for calibrating mathematical models describing pantographic structures under dynamic loadings.
\end{abstract}

Keywords Pantographic metamaterials $\cdot$ Parametric investigation · Additive manufacturing $\cdot$ Complex structures . Experimental tests

\section{Introduction}

Since the advent and continuous progress of additive manufacturing techniques, new horizons in terms of analysis of the mechanical behavior of materials and design of new materials have been opened. By employing the most advanced processes it is now possible to create objects with complex geometries at very small length scale. Arranging such complex objects in a periodic pattern, playing the role of microor nano- scale building block, results in micro-structured materials, also called metamaterials, whose macroscopic mechanical behavior is strongly dependent on the characteristics of the kinematic field of the given micro-structure. Barchiesi et al. [1, 2] This influences the research in the field of innovative materials as we are now able to endow them with a micro-structure, which is potentially customizable and tunable according to the applications to be addressed. However, the new promising possibilities require the definition of more refined mathematical models, involving

A. Misra

amisra@ku.edu

Extended author information available on the last page of the article. detailed kinematic fields and higher order gradient terms in their equations of motion to capture their unusual behavior. Examples are represented by pantographic structures [3-7], for which their exotic behavior has to be described with higher gradient continuum theories [8-10] or micromorphic theories [11, 12], granular media [13-19], auxetic material $[20,21]$ and functionally graded material $[22,23]$.

Pantographic structures have recently been investigated particularly from a theoretical, mechanical and manufacturing point of view because of their peculiar capability to undergo large tensile deformation while remaining in elastic regime [3]. The design of such metamaterial comes from a mathematical understanding of the related mechanical problem and considerations on the insufficiency of classical theories to describe materials with complex micro-structure, and it has been conceived so that its deformation energy depends on the second gradient of the displacement $[7$, 24-26]. Morphologically, the pantographic system can be described as a double array of mutually orthogonal beams, also called fibers, interconnected by elastic cylinders at intersection points, called pivots [27].

Earlier investigations can be found in a series of papers (see e.g. [5, 27-31]) in which the authors address the problem of determining the mechanical properties of pantographic metamaterials. Various mathematical models have 
also been proposed which can be classified into two-types i) discrete, as in [27, 29, 32-36], wherein a finite set of rotational and extensional springs are introduced to describe the complex deformation phenomenon occurring in the microstructure; or ii) continuous, as in [27, 33, 37, 38], which can be further distinguished into purely continuous ones, wherein a generalized plate model is used (of the same kind of those proposed e.g. in [11, 12], and into hybrid discrete/continuous ones, wherein beams (i.e. 1D continua) form lattices by means of interconnecting pivots placed at finite distances (see [39-42]). The main motivation of these works is to find a reasonable compromise between predictive capacity and computational feasibility in analyzing pantographic structures. Both continuous and discrete models demonstrate their own peculiarities in facing the problem and some comparisons have been recently presented where the validation of the models is demonstrated by using experimental results [29, 43, 44]. It is noteworthy that the behavior observed during tensile test [36, 44, 45], shear test [45-47] and also torsion test [45] conducted on specimens of pantographic structures (as the kind described in [27]) is well represented by the aforementioned models. However it is not clear how the geometric features of the pantographic micro-structure affect the mechanical behavior of the specimens tested yet. An understanding of the role of geometrical parameters on the macroscopic behavior of pantographic structures seems indispensable for the purpose of designing of such structures with desired functionalities. Indeed, regardless of the nature of the approach (continuous or discrete) used to forecast the behavior of the system under various load and boundary conditions, it is necessary to estimate the relevant constitutive parameters on which the deformation energy function depends. Also, an investigation on pantographic beam structures with relatively small number of cells could be, according to the theory developed in [48], useful to determine information about the extent to which continuum modeling can approximate more spatially extended structures. We believe that better identification schemes have to be devised for the aim of identifying the mechanical properties and achieving structural optimizations. Such identification schemes require experimental results sufficient for calibrating mathematical models.

In this paper we present a series of results obtained from a set of experimental tests performed on specimens of pantographic structure. Rather than using larger samples, the specimens considered herein can be defined as the elementary module of the pantographic micro-structure. Tensile, compression, shear and tensile relaxation tests are performed on a large set of polyamide specimens whose geometric features are presented in "Fabrication and Experimental Setup". In the same section we present the prescriptions of the tests and the tools employed. "Results and Discussion" is devoted to the results and corresponding discussions of the experimental data. In the conclusion section an outline about the results is given with considerations regarding future studies.

\section{Fabrication and Experimental Setup}

The specimens considered herein represent the unit cell of the micro-structure employed to build a larger pantographic structure (Table 1). The geometry of the objects was initially generated employing the CAD software SolidWorks (Dassault System SolidWorks Corporation, Waltham, MA, USA). The specimens were thereafter printed using 3D printer Formiga P 100 (EOS GmbH, Munich, Germany) at the University of Technology, Warsaw, Poland. The 3D printer uses a selective laser sintering (SLS) technology to produce the pantographic structure out of polyamide powder (PA2200), where the average grain size of the powder used was $56 \mu \mathrm{m}$. The complete set of specimen contains thirty three objects characterized by different values of the geometric parameters (see Fig. 1). In order to easily refer to each specimen, depending on the value assumed by the parameter $p$, we arrange the specimens with $p=5 \mathrm{~mm}$ in a group A and the specimens with $p=8$ $\mathrm{mm}$ in a group B. Furthermore, an index $i=1,2,3,4$ is assigned to each specimen depending on the length of the pivot, which indicates sample type. Details about the sample type, number and geometric features can be found in Table 2. For each sample type a tensile, compression, tensile relaxation and a shear test were performed. A Bose ElectroForce 3200 testing-device controlled by the software WinTest Material Testing System was used to perform all the experiments presented in the following. The load cell used to measure the reaction force values has a measurement range of $\pm 22 \mathrm{~N}$, a measurement uncertainty of $0.1 \%$ and precision of $0.001 \mathrm{~N}$. All the tests were performed in displacement control, which is measured with the builtin transducer with the range of $\pm 6.5 \mathrm{~mm}$, a measurement uncertainty of $0.1 \%$ and precision of $0.001 \mathrm{~mm}$. For evaluations on the deformation fields by means of digital image correlation technique (DIC), pictures were taken during the tensile, compression and shear tests. DIC along with relevant discussions on the deformation field, similar to [35], will be pursued in a separate paper in the future. To this end the specimens were sprayed on their surface with a black spray -to make a speckle pattern- prior to the testing, and a NIKON D300 digital camera was used to take consecutive

Table 1 Constant parameters shared by all the specimens

\begin{tabular}{llllll}
\hline $\begin{array}{l}a \\
(\mathrm{~mm})\end{array}$ & $\begin{array}{l}b \\
(\mathrm{~mm})\end{array}$ & $\begin{array}{l}d \\
(\mathrm{~mm})\end{array}$ & $\begin{array}{l}L \\
(\mathrm{~mm})\end{array}$ & $\begin{array}{l}\theta \\
(\mathrm{rad})\end{array}$ & $\begin{array}{l}\phi \\
(\mathrm{rad})\end{array}$ \\
\hline 1.2 & 1 & 1 & 5 & $\frac{\pi}{2}$ & $\frac{\pi}{4}$ \\
\hline
\end{tabular}


Fig. 1 Parameters describing the pantographic structure

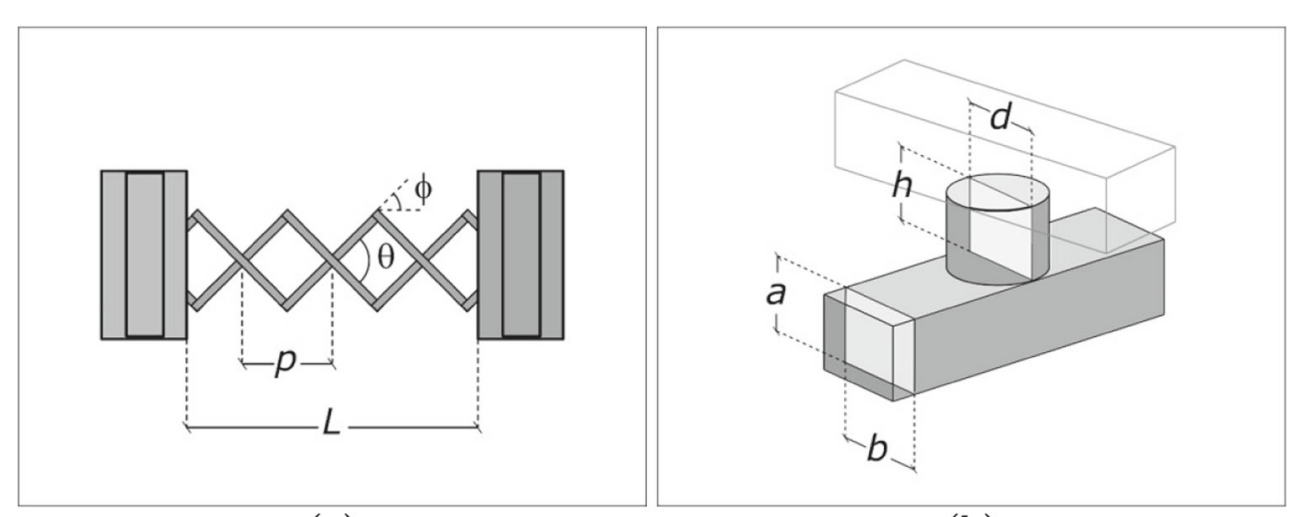

(a)

(b)

pictures at fixed time intervals with image resolution of 4288 by 2848 pixels. The tensile test is experimentally carried out by keeping fixed one side of the specimen and applying an axial displacement on the other side. For this test, the imposed values of displacement are $4 \mathrm{~mm}$ and 6 $\mathrm{mm}$, for groups A and B respectively, at the rate of $0.1 \mathrm{~mm} / \mathrm{s}$. A similar setup has been used to conduct the compression test but in this case, obviously, the imposed displacement has opposite sign. The compression displacements applied to the specimens of group A and group B are of $10 \mathrm{~mm}$ and $12 \mathrm{~mm}$ respectively, at a rate of $0.1 \mathrm{~mm} / \mathrm{s}$. The experimental realization of the shear test is carried out by fixing the specimen on one side while on the other side a tangential displacement is applied. The displacement occurs in the plane on which the specimen lies. The specimens of both groups A and B are displaced up to $10 \mathrm{~mm}$ at the rate of $0.1 \mathrm{~mm} / \mathrm{s}$. The tensile relaxation test, whose setup is similar to that of the tensile test, prescribes the application of three successive load levels, starting from $2 \mathrm{~mm}$ for group A and from $4 \mathrm{~mm}$ for group B, being the increase of displacement of each load step equal to $1 \mathrm{~mm}$. Every load level is maintained constant for eight hours. This duration has been selected after a previously conducted test on a specimen for two days which showed a great portion of relaxation occurs in the first eight hours. One has to remark that the fulfillment of all the devised experiments required to design and 3D print some support structures (see Fig. 2) in order to hold the specimens during the tests. For the tensile, compression and tensile relaxation test, two clamps have been printed employing a Mojo 3D printer (FDM Fused Deposition Modeling, by Stratasys) using as constituent material an acrylonitrile butadiene styrene (ABS) thermoplastic (Fig. 2(a)). Similarly, for the shear test a rigid support structure and two different clamps have been created by employing the same $3 \mathrm{D}$ printer and constituent material. The measurement error introduced by the deformability of these support objects was considered negligible following some numerical simulations of the experiments in FE software ABAQUS.

\section{Results and Discussion}

The results presented here comprise a complete set of tests sufficient to calibrate pantographic models, and therefore can be used as benchmarks for the developed theoretical models. In the following, we briefly comment the peculiarities observed. Note that in the following we will use the term stiffness to refer to the trend of the values generally assumed by the ratio between force and imposed displacement, but no specific force-displacement relation is meant.

In Fig. 3 the results of the tensile test for the two groups of specimens are shown. In the plots related to group A in Fig. 3(a) one can notice that the stiffness of the sample is inversely proportional to length of the pivots. Indeed for a given value of displacement, among those considered in the experiments, the force decreases progressively from the maximum value, measured for the sample A1, to the minimum value, measured for the sample A4. Furthermore, observing singularly the data for each specimen, the curves related to A2, A3 and A4 have almost a linear behavior while for the specimen A1 a hardening tract arises after 2 $\mathrm{mm}$ of displacement. This could be attributed to the plastic deformation of the pivots or increased axial extension of the

Table 2 Type of specimen, number and values of the distinctive parameters for each type of specimen

\begin{tabular}{llll}
\hline Specimen type & Number of specimens & $\begin{array}{l}p \\
(\mathrm{~mm})\end{array}$ & $\begin{array}{l}h \\
(\mathrm{~mm})\end{array}$ \\
\hline $\mathrm{A} 1$ & 4 & 5 & 1 \\
$\mathrm{~A} 2$ & 3 & 5 & 1.5 \\
$\mathrm{~A} 3$ & 4 & 5 & 2 \\
$\mathrm{~A} 4$ & 4 & 5 & 3 \\
$\mathrm{~B} 1$ & 5 & 8 & 1 \\
B2 & 4 & 8 & 1.5 \\
B3 & 5 & 8 & 2 \\
B4 & 4 & 8 & 3 \\
\hline
\end{tabular}


Fig. 2 Experimental setup of the tests for a tensile, compression and tensile relaxation tests $\mathbf{b}$ shear test

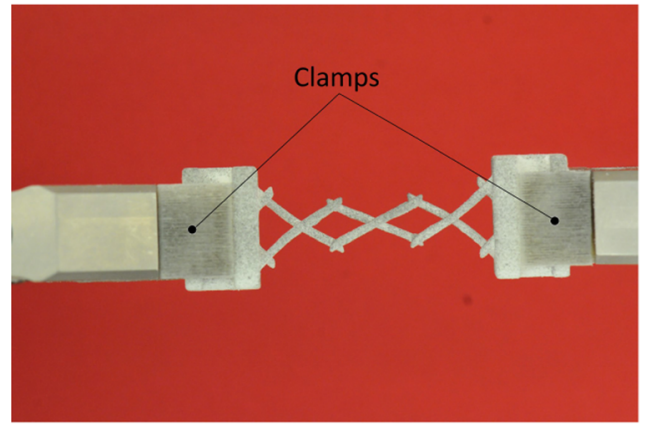

(a)

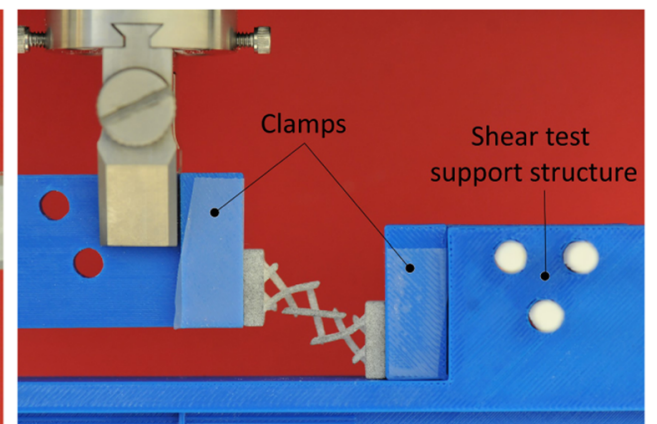

(b) central beams for the specimen A1. In Fig. 3(b) the plots for the tensile test related to the specimen of the group B are shown. Also in this case the data depicts an overall inverse proportionality between the stiffness and the length of the pivots, but for the specimen B1 the behavior is different. The reaction force values decrease gradually from $\mathrm{B} 2$ to B4 but the curve of B1 overlaps the plot of B4 for the most part and it has a hardening part starting from about 4 $\mathrm{mm}$ of elongation. With a more detailed look at the data, the specimens B3 and B4 seem to have linear behaviors while for the specimens B1 and B2 an incipient hardening behavior can be seen for higher values of displacement.

The plots in Fig. 4 give information about the force trend depending on the length of the pivots, for the tensile test. Specifically, in each plot the abscissa axis reports the sample type while the ordinate axis reports the measured force, which is evaluated for four different values of imposed displacements. In Fig. 4(a), which shows the data related to the group A, it can be observed that for a given applied displacement, the force exerted is decreasing with the length of the pivot, which represents the inverse proportionality mentioned above. On the contrary, the specimens of group $\mathrm{B}$ do not follow the aforementioned inverse proportionality. Indeed, in Fig. 4(b), it is noticeable that there is a maximum force value corresponding to the specimen B2. This aberration deserves mathematical justification and will be further investigated in future works.
In Fig. 5 the experimental data of the compression tests are plotted for both group A and group B. In Fig. 5(a), which shows the data regarding the group $\mathrm{A}$, it is hard to recognize a linear stage as the behavior seems to be nonlinear even for small values of the imposed displacement. Up to 6 $\mathrm{mm}$ of compression, all the curves, whose values are close to each other, describe a softening behavior. After $6 \mathrm{~mm}$ of compression, the behavior of the samples changes and reaction forces increase rapidly, describing a hardening behavior. An interpretation of this observation is attempted in the following with the help of the pictures taken during the test. We can remark that the group A observes the inverse proportionality relation between the stiffness of the sample and the length of the pivots. Similar considerations can be made looking at Fig. 5(b). Indeed, the plots of the compression test for group B describe a softening behavior with a not easily recognizable initial linear stage and a hardening behavior starting from about $10 \mathrm{~mm}$ of displacement. Similar to the results of tensile test, the sample B2 leads to the highest values of reaction force. We remark that the curve related to sample B1 is closer to the values assumed by sample B4 up to $10 \mathrm{~mm}$ of compression while starts to rise fast over this value, overlapping the plot of sample B2 for higher value of compression. The higher stiffness of sample B2 can be observed in the Fig. 6(b), where the force values recorded at several displacement values are plotted with respect to the length of the pivots. It
Fig. 3 Plots of the data from experimental tensile test for $\mathbf{a}$ group A b group B

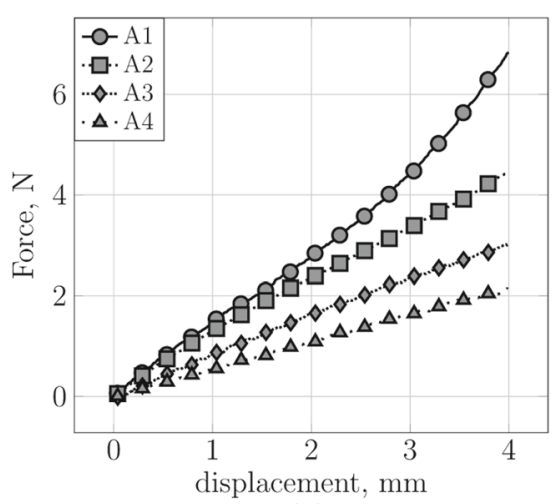

(a)

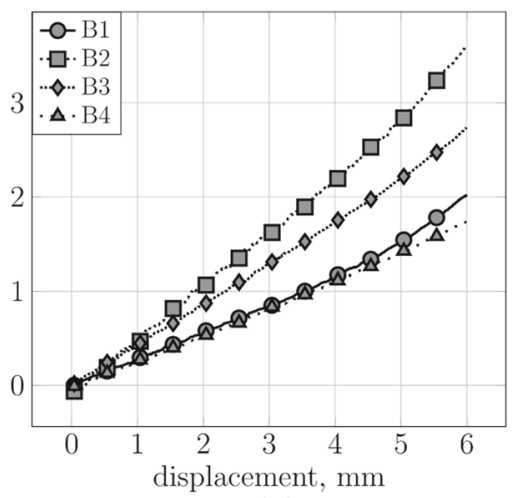

(b) 
Fig. 4 Interpolation of the force values with respect to the length of the pivots in tensile tests. Each line refers to a specific value of the imposed displacement ("disp" in the legend) for a group A b group B

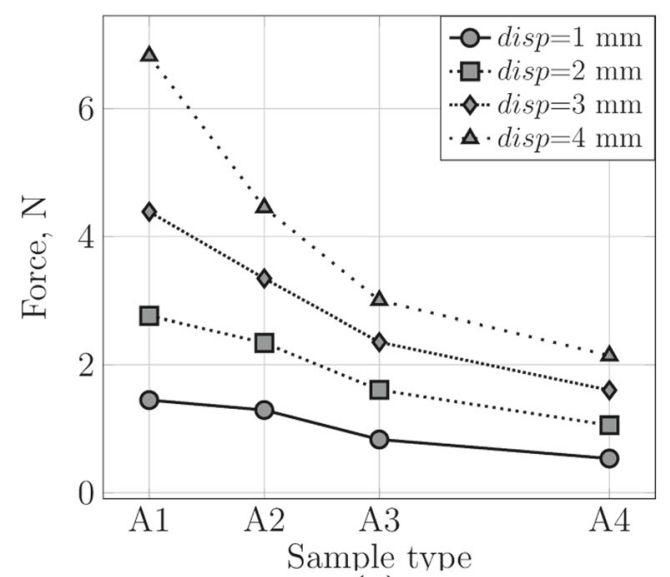

(a)

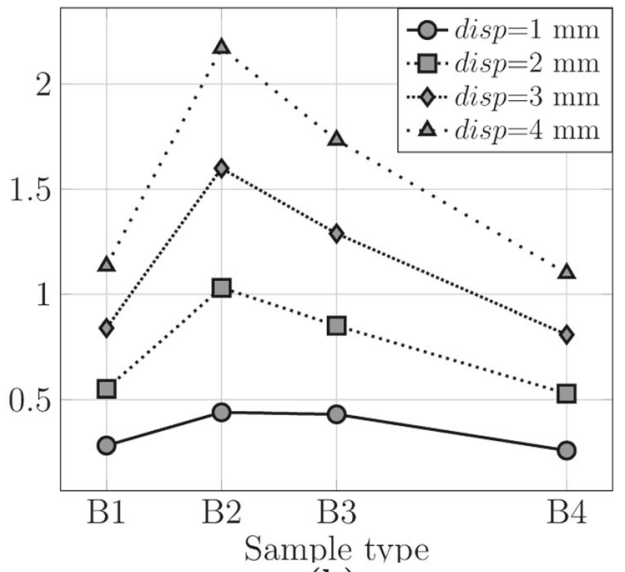

(b) can be noted that in correspondence of sample B2 the plots have a maximum. In Fig. 6(a), a similar plot is shown for group A which for every displacement level observes the inverse proportionality between stiffness and length of the pivots.

The data related to the shear test are plotted in Fig. 7. The shear stiffness is inversely proportional to the length of the pivots for both the groups A and B, but also in this case the sample B1 behaves differently. In Fig. 7(b), it can be noted that the plot of the data for the shear test regarding the sample B1 is between the plots of samples B2 and B3. Considering separately the two groups, in Fig. 7(a) the behavior of all the samples belonging to group A is linear for the most part and has an incipient hardening part for higher values of the imposed displacement, more evident for the sample A1. The plots of the group B reported in Fig. 7(b) show that all the samples have linear behavior within the entire range of displacement. It is anticipated that for a larger displacement, group B also shows a nonlinear hardening effect. The plots in Fig. 8 give information about the stiffness trend of the samples varying the length of the pivots, for both group A and B. The existence of local extrema in the space of the geometrical parameters can be noted for sample type B1

Comparisons between the tensile, compression and shear tests are shown in Fig. 9 for all the specimens. It can be noted that, in all the graphs of Fig. 9, the highest stiffness is observed during the tensile test, the lowest during the shear test and intermediate values during the compression test.

In order to give an interpretation of the behavior of each pantographic structure undergoing tensile, compression and shear tests, we plot in Fig. 10 the tensile, compression and shear tests related to the sample A1. The numeric marks from 1 to 5 plotted in Fig. 10 are related to the corresponding picture number in Fig. 11 for each test, respectively. The pictures in Fig. 11 visualize the equilibrium shape for the considered state of the sample in the force-displacement plots. A main observation emerges by looking at Fig. 10(a) and at the corresponding line in Fig. 11. Hardening behavior can be observed for the two cases of shear and tension. For the compression test, however, a softening behavior is observable. The hardening behavior noticed between steps 4 and 5 in the compression test Fig. 11(b) is due to natural contact between the constituting beams of the
Fig. 5 Plots of the data from experimental compression test for $\mathbf{a}$ group A $\mathbf{b}$ group B

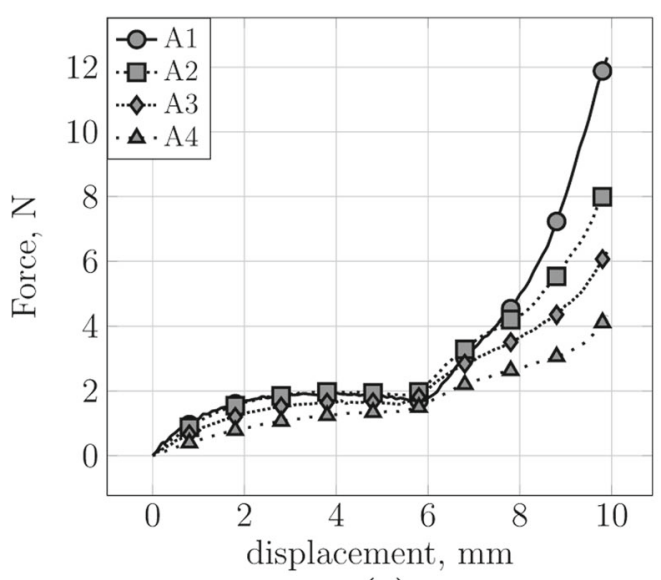

(a)

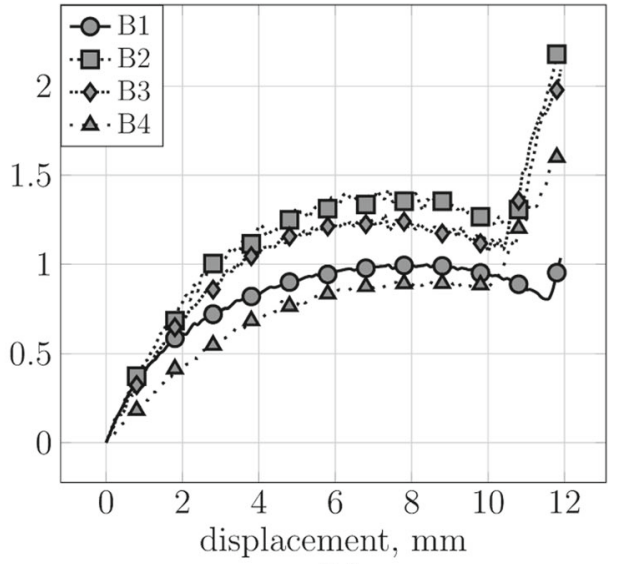

(b) 
Fig. 6 Interpolation of the force values with respect to the length of the pivots in compression tests. Each line refers to a specific value of the imposed displacement ("disp" in the legend) for a group A b group B

Fig. 7 Plots of the data from experimental shear test for a group A b group B

Fig. 8 Interpolation of the force values with respect to the length of the pivots in shear tests. Each line refers to a specific value of the imposed displacement ("disp" in the legend) for a group A b group B

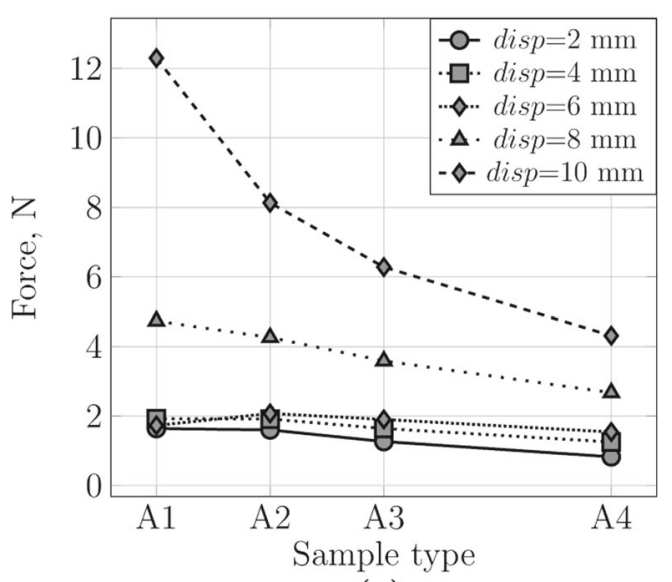

(a)

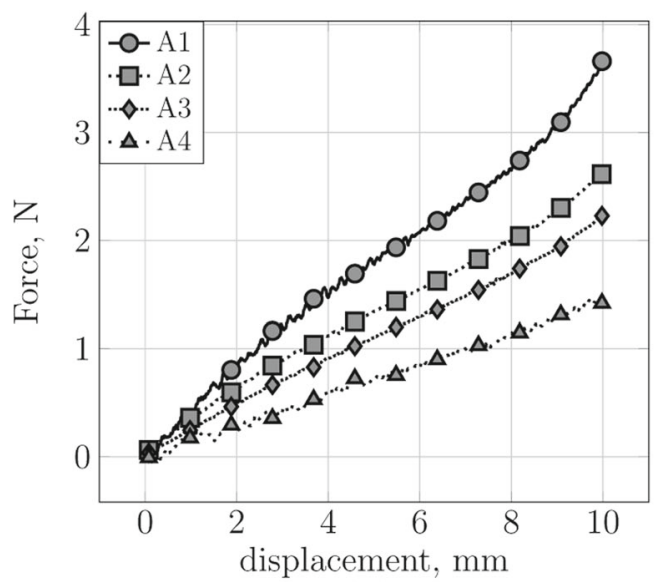

(a)

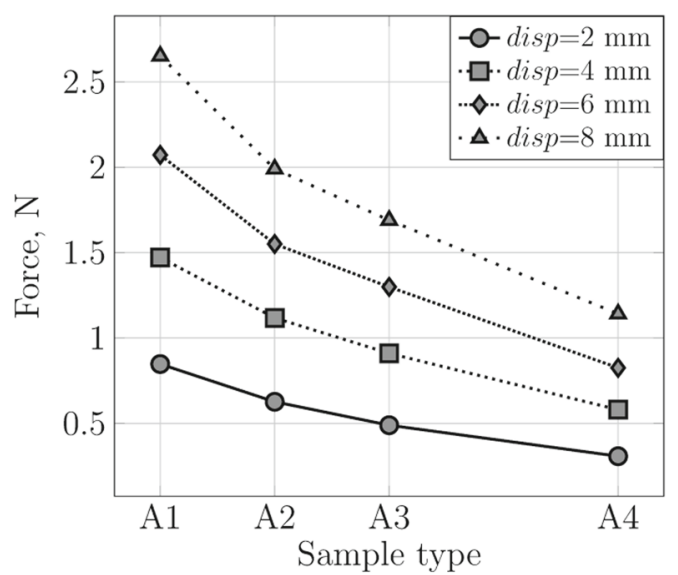

(a)

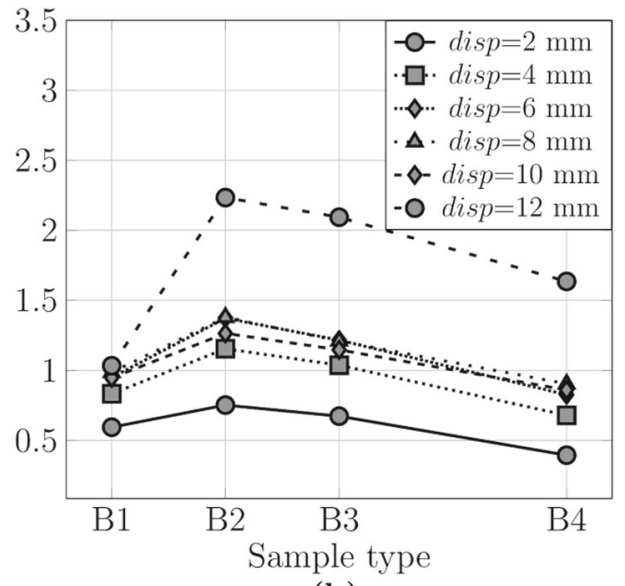

(b)

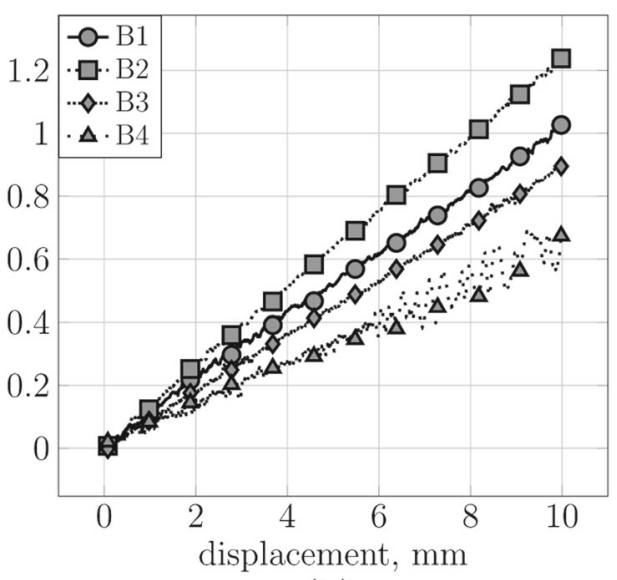

(b)

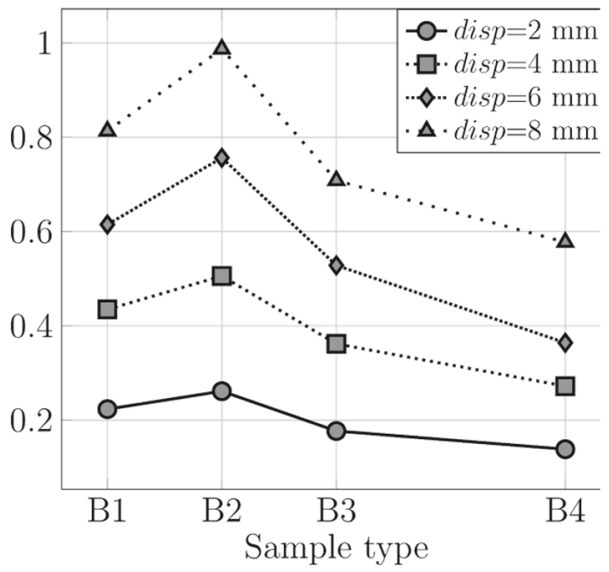

(b) 
Fig. 9 Comparison of the

experimental data of all the

samples between tensile test,

compression test and shear test

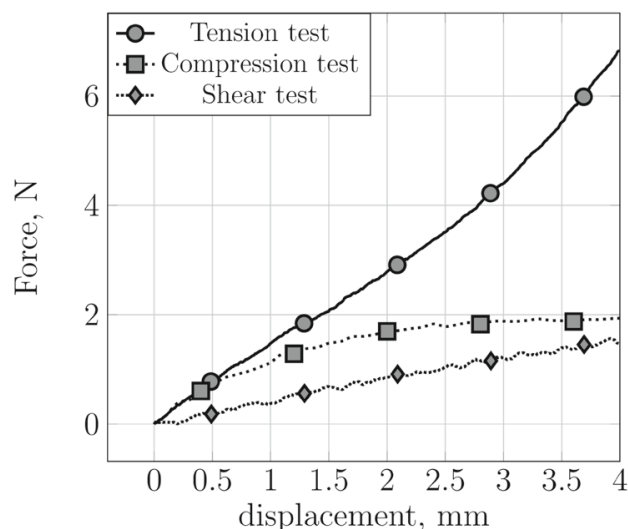

(a) A1

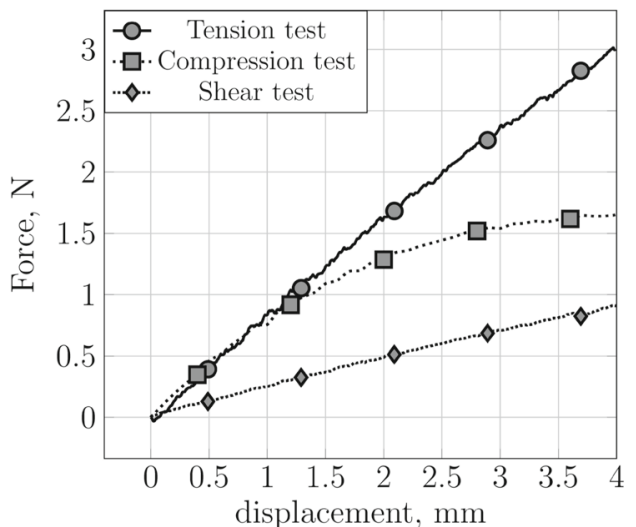

(c) A3

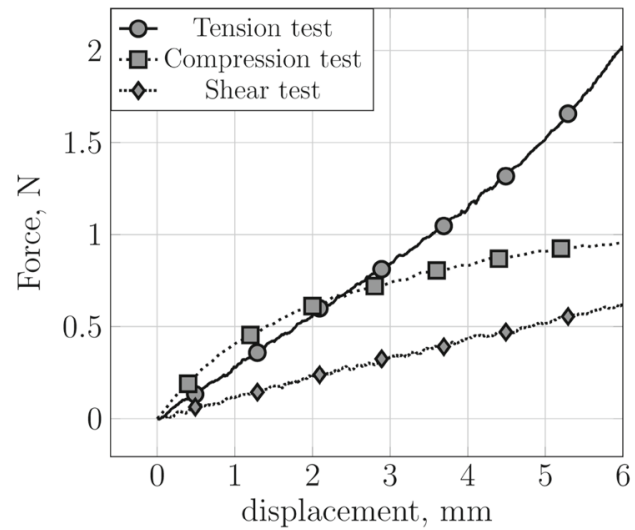

(e) B1

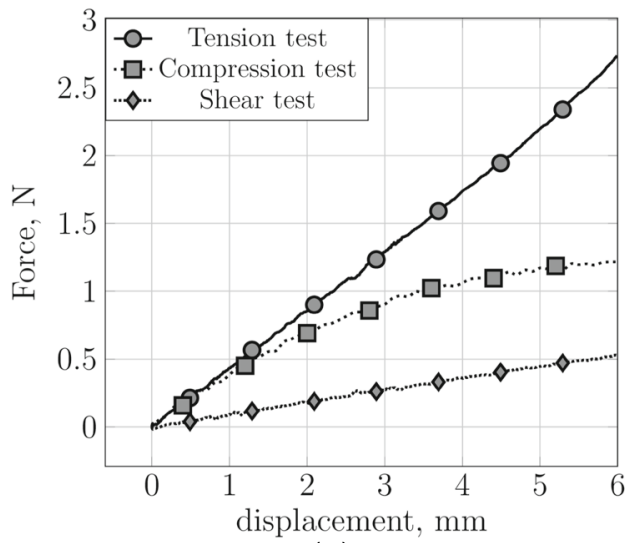

(g) B3

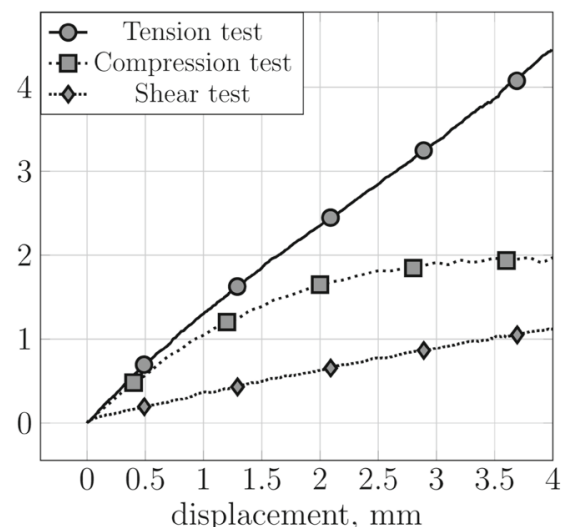

(b) A2

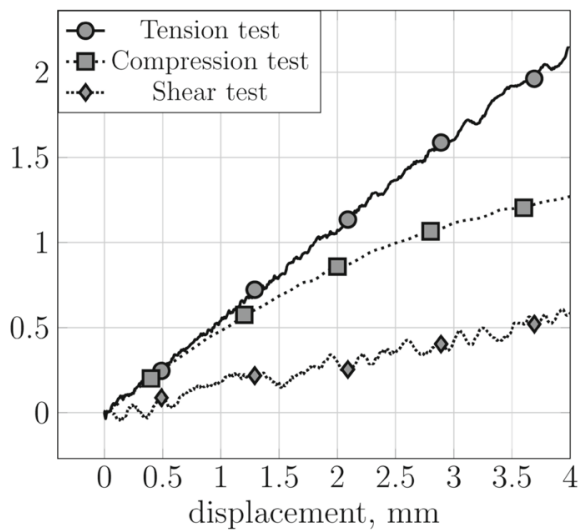

(d) $\mathrm{A} 4$

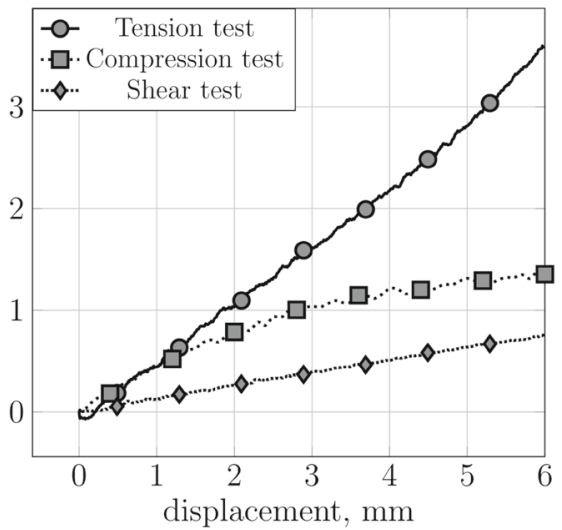

(f) B2

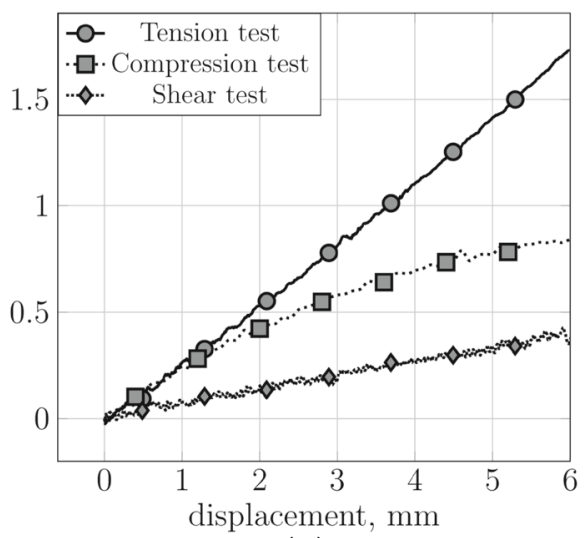

(h) B4 
Fig. 10 a Tensile b compression and $\mathbf{c}$ shear plots of force versus displacement for the sample A1

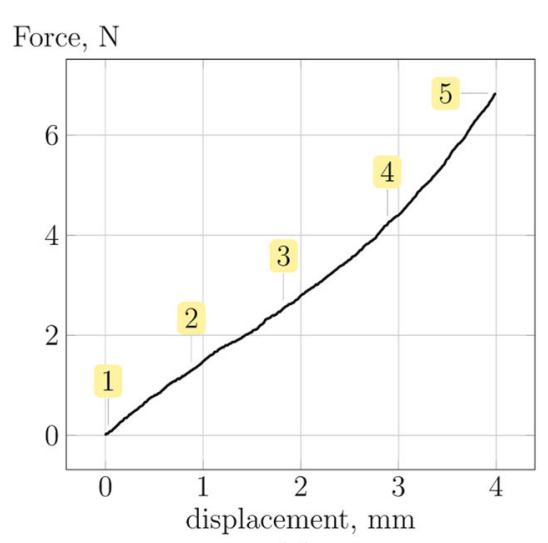

(a)
Force, N

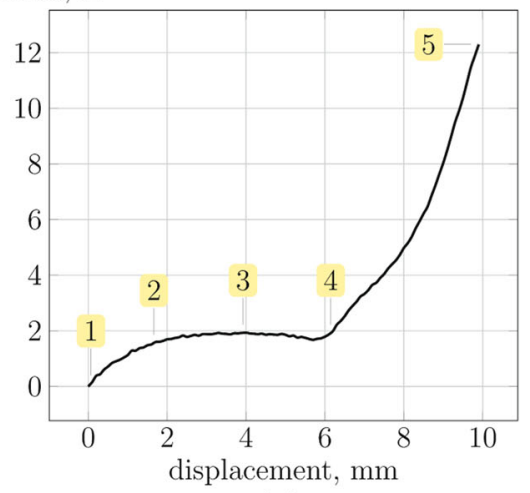

(b)

Force, N

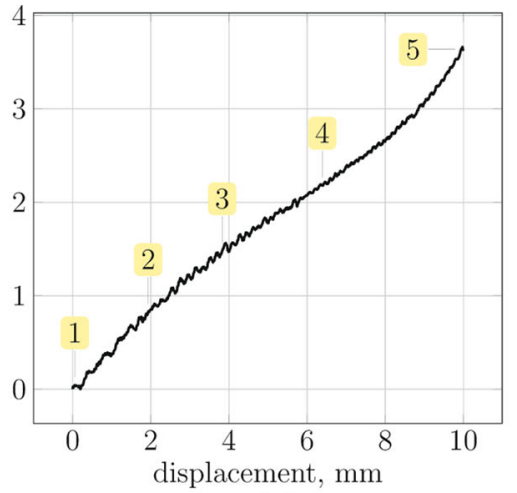

(c)

Fig. 11 Pictures displaying the deformation of sample A1 under tensile, compression and shear test at five different stages

(a)

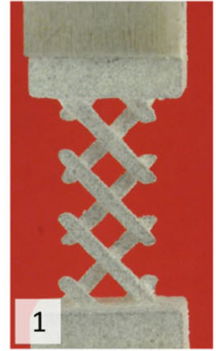

(b)
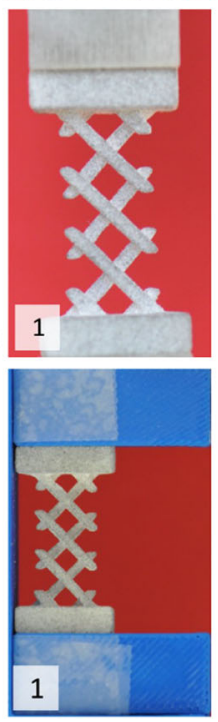
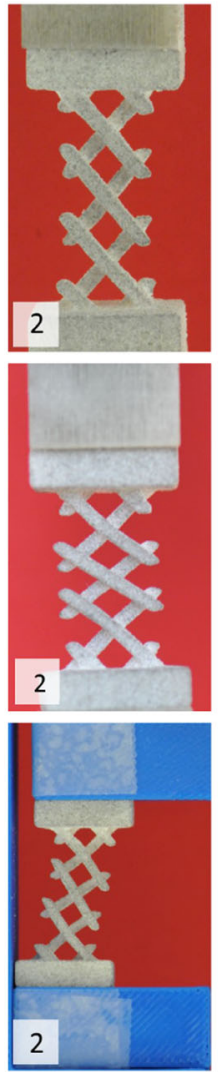
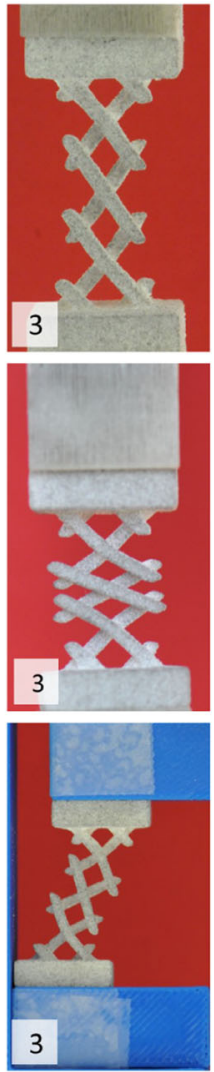
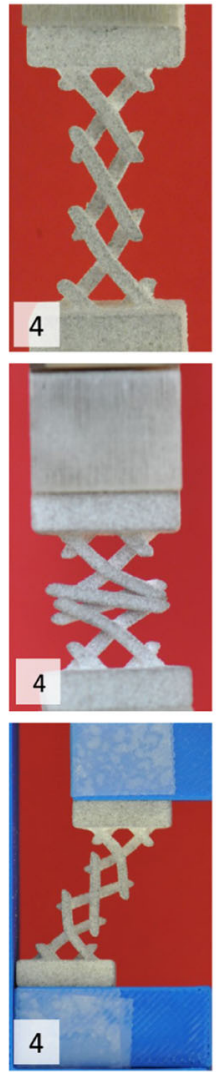
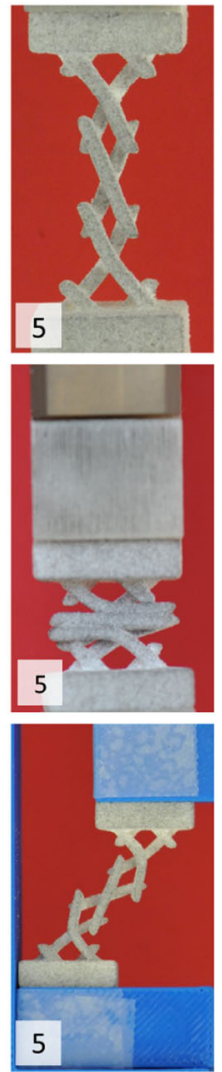
Fig. 12 Plots of the data from experimental tensile relaxation test for a group A b group B

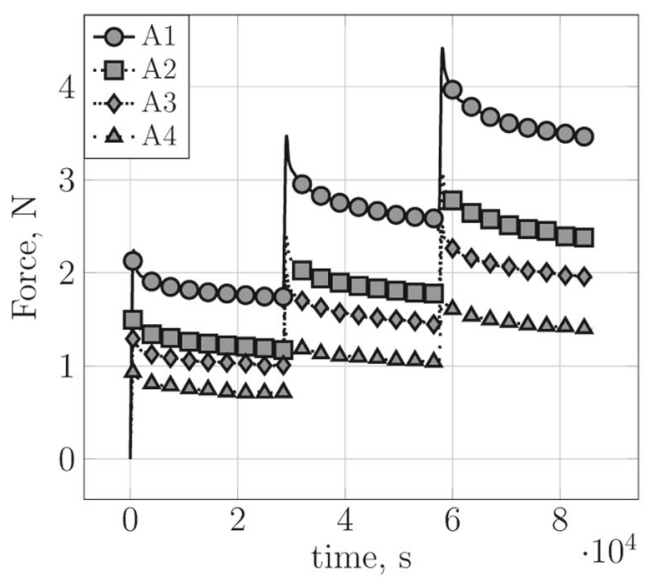

(a)

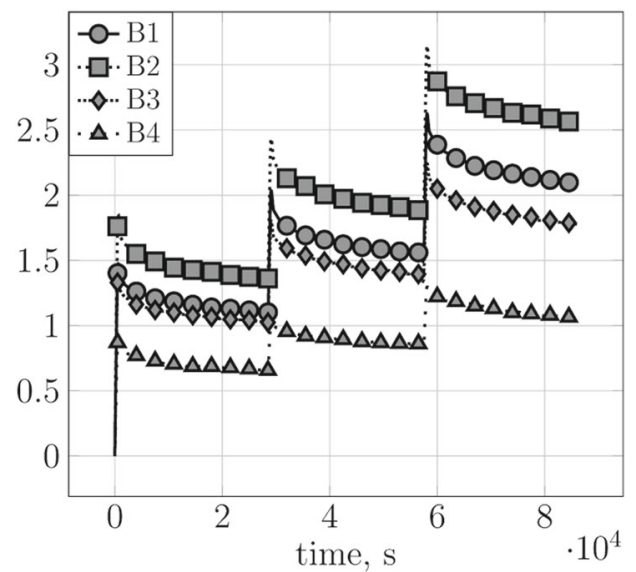

(b) pantographic micro-structure, and is merely plotted for completeness. Another interesting remark is that in all three different tests reported in Fig. 11, the central beams of each specimen experience indiscernible bending deformation and, primarily, undergo rigid body motion. As is observed in [27], major part of the bending and torsional energies are therefore stored in beams closer to the boundaries and pivots in central regions of the structure, respectively.

The data related to the tensile relaxation test are shown in Fig. 12 for both group A and group B. We recall from "Introduction" that the test prescribes three displacement steps, starting from $2 \mathrm{~mm}$ to $4 \mathrm{~mm}$ for group A, and starting from $4 \mathrm{~mm}$ to $6 \mathrm{~mm}$ for group B, with a displacement increment of $1 \mathrm{~mm}$ applied at the rate of $0.1 \mathrm{~mm} / \mathrm{s}$. Every load is maintained constant for eight hours. In Fig. 12, reaction force versus time is plotted for each of the specimen tested. There is a good agreement between the the specimens tested from group A in Fig. 12(a) and their counterparts for the tensile test in Fig. 3(a). However, for the group B, the plot for the specimens B1 in Fig. 12(b) lies closer to the one plotted for the specimen B3 rather than B4, which is different from the same geometry behavior reported above in Fig. 3(b).
This observation may be attributed to the inevitable existence of fabrication defects, which makes different samples with the same geometry different in behavior.

The stress versus time data of sample A1 has been fitted using a Prony series. The Generalized Maxwell model, also known as the Wiechert model (it takes into account that the relaxation does not occur at a single time, but at a distribution of times), has been considered to model the linear viscoelasticity, which is assumed to be valid. In order to validate this assumption the tensile relaxation module $E$, which is the ratio between the force and the constant applied displacement, versus time is plotted in Fig. 13(a) for the three load steps considered in the experiment. The observed overlapping of the three plots verifies the linear viscoelasticity assumption. In Fig. 13(b) the comparison between the experimental data and the Prony series $F(t)$ coming from the fitting procedure is shown. The function $F(t)$ defines the relation between force and the time and has the following general form

$F(t)=F_{0}+\sum_{n=1}^{n} F_{n} e^{-\frac{t}{\tau_{n}}}$
Fig. 13 a Tensile relaxation modulus for the three steps of relaxation test on specimen A1. b Experimental and fitted relaxation behavior of the specimen A1

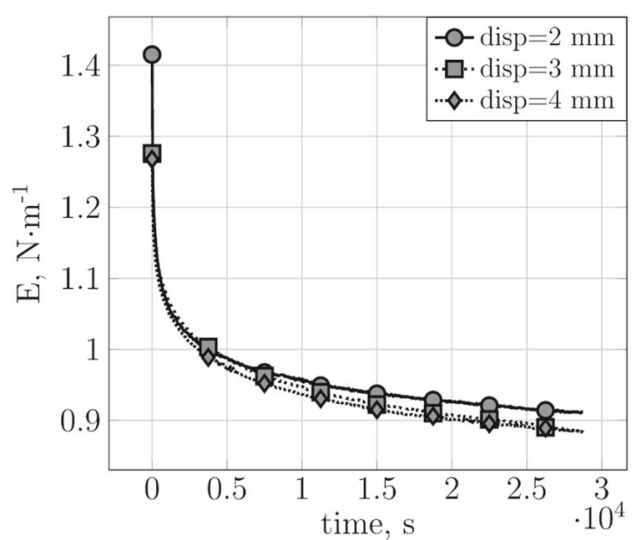

(a)

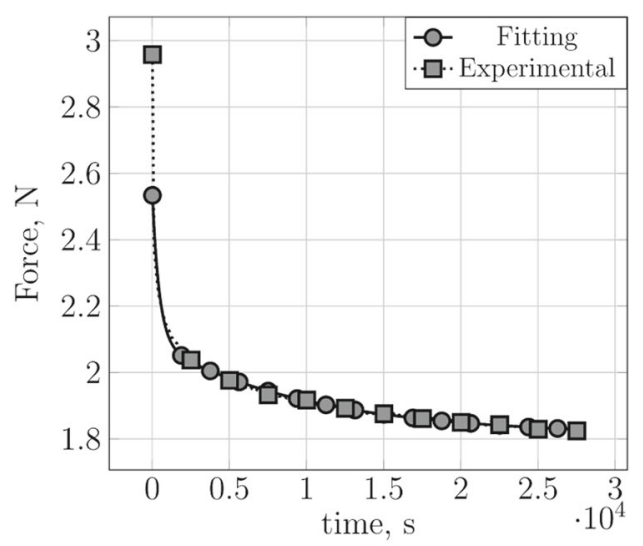

(b) 
Table 3 Tensile relaxation Prony series terms for sample A1 for $2 \mathrm{~mm}$ displacement

\begin{tabular}{|c|c|c|c|c|c|c|c|c|c|c|}
\hline Type & Step & $\begin{array}{l}F_{0} \\
(\mathrm{~N})\end{array}$ & $\begin{array}{l}F_{1} \\
(\mathrm{~N})\end{array}$ & $\begin{array}{l}F_{2} \\
(\mathrm{~N})\end{array}$ & $\begin{array}{l}F_{3} \\
(\mathrm{~N})\end{array}$ & $\begin{array}{l}F_{4} \\
(\mathrm{~N})\end{array}$ & $\begin{array}{l}\tau_{1} \\
(\mathrm{sec})\end{array}$ & $\begin{array}{l}\tau_{2} \\
(\mathrm{sec})\end{array}$ & $\begin{array}{l}\tau_{3} \\
(\mathrm{sec})\end{array}$ & $\begin{array}{l}\tau_{4} \\
(\mathrm{sec})\end{array}$ \\
\hline A1 & $1^{\text {st }}$ & 1.826 & 0.2479 & 0.4500 & 0.2031 & 0.2308 & 10000 & 500.0 & 0.0010 & 0.0001 \\
\hline A1 & $2^{\text {nd }}$ & 2.633 & 0.5335 & 0.4712 & 0.2186 & 0.2186 & 10720 & 627.0 & 0.0010 & 0.0001 \\
\hline A1 & $3^{\text {rd }}$ & 3.537 & 0.6679 & 0.5842 & 0.2810 & 0.2810 & 8581 & 492.0 & 0.0010 & 0.0001 \\
\hline A2 & $1^{\mathrm{st}}$ & 1.249 & 0.2723 & 0.2718 & 0.0775 & 0.1465 & 7882 & 256.9 & 0.0010 & 0.0001 \\
\hline A2 & $2^{\text {nd }}$ & 1.828 & 0.3663 & 0.3154 & 0.1016 & 0.1211 & 9712 & 566.5 & 0.0010 & 0.0001 \\
\hline A2 & $3^{\text {rd }}$ & 2.427 & 0.5163 & 0.4001 & 0.1551 & 0.1622 & 9895 & 446.1 & 0.0010 & 0.0001 \\
\hline $\mathrm{A} 3$ & $1^{\mathrm{st}}$ & 1.038 & 0.2039 & 0.2682 & 0.0786 & 0.1473 & 8816 & 530.7 & 0.0010 & 0.0001 \\
\hline A3 & $2^{\text {nd }}$ & 1.486 & 0.3636 & 0.2432 & 0.0667 & 0.0662 & 9271 & 528.1 & 0.0010 & 0.0001 \\
\hline $\mathrm{A} 3$ & $3^{\text {rd }}$ & 1.997 & 0.3969 & 0.3057 & 0.0977 & 0.0970 & 8821 & 500.3 & 0.0010 & 0.0001 \\
\hline A4 & $1^{\mathrm{st}}$ & 0.7159 & 0.1831 & 0.1731 & 0.0597 & 0.0593 & 9222 & 434.5 & 0.0010 & 0.0001 \\
\hline A4 & $2^{\text {nd }}$ & 1.0524 & 0.2116 & 0.2000 & 0.0122 & 0.0130 & 9724 & 323.0 & 0.0010 & 0.0001 \\
\hline A4 & $3^{\text {rd }}$ & 1.417 & 0.2623 & 0.1777 & 0.0568 & 0.0562 & 9086 & 486.4 & 0.0010 & 0.0001 \\
\hline B1 & $1^{\mathrm{st}}$ & 1.113 & 0.2555 & 0.3151 & 0.0804 & 0.0806 & 8425 & 235.1 & 0.0010 & 0.0001 \\
\hline B1 & $2^{\text {nd }}$ & 1.549 & 0.3025 & 0.2354 & 0.1014 & 0.1010 & 9924 & 522.5 & 0.0010 & 0.0001 \\
\hline B1 & $3^{\mathrm{rd}}$ & 2.101 & 0.3733 & 0.3114 & 0.1458 & 0.1453 & 8847 & 444.1 & 0.0010 & 0.0001 \\
\hline B2 & $1^{\mathrm{st}}$ & 1.411 & 0.3119 & 0.3696 & 0.1562 & 0.1566 & 7598 & 344.8 & 0.0010 & 0.0001 \\
\hline B2 & $2^{\text {nd }}$ & 1.925 & 0.3534 & 0.2498 & 0.0890 & 0.0885 & 9064 & 457.8 & 0.0010 & 0.0001 \\
\hline B2 & $3^{\mathrm{rd}}$ & 2.593 & 0.3845 & 0.3436 & 0.1338 & 0.1448 & 9792 & 573.2 & 0.0010 & 0.0001 \\
\hline B3 & $1^{\mathrm{st}}$ & 1.046 & 0.2149 & 0.2905 & 0.1180 & 0.1170 & 8779 & 426.9 & 0.0010 & 0.0001 \\
\hline B3 & $2^{\text {nd }}$ & 1.405 & 0.2795 & 0.1602 & 0.0534 & 0.0530 & 9676 & 485.2 & 0.0010 & 0.0001 \\
\hline B3 & $3^{\mathrm{rd}}$ & 1.787 & 0.3443 & 0.2147 & 0.0787 & 0.0789 & 10150 & 520.7 & 0.0010 & 0.0001 \\
\hline B4 & $1^{\mathrm{st}}$ & 0.6518 & 0.1715 & 0.1566 & 0.0508 & 0.0511 & 942.1 & 471.0 & 0.0010 & 0.0001 \\
\hline B4 & $2^{\text {nd }}$ & 0.8584 & 0.1396 & 0.0713 & 0.0223 & 0.0223 & 887.4 & 398.3 & 0.0010 & 0.0001 \\
\hline B4 & $3^{\text {rd }}$ & 1.069 & 0.2029 & 0.0934 & 0.0238 & 0.0233 & 964.0 & 221.7 & 0.0010 & 0.0001 \\
\hline
\end{tabular}

where $F_{0}$ is the force when the specimen is completely relax, $\tau_{n}$ is the characteristic relaxation time, and $F_{n}$ is the force exerted by the $n$-th brace of the model. We report in Table 3 the values of the parameters identified for each Prony series terms for the specimen A1, along with the other specimen types for all the three steps of loading. Note that for the steps two and three of the loading, a shift in time has been done such that the start of the step coincides with zero time. The identified parameters in Tab. 3 have been computed using a least square approach, and the minimum values for the third and fourth characteristic times were chosen to be 0.001 and 0.0001 seconds, respectively. Smaller values for the second and third characteristic times changed the results only negligibly. An analysis on the effect of characteristic times less than 0.01 reveals their major effect only in the first few seconds of the relaxation. However, the existence of the third and fourth terms proved necessary to properly model the small time range behavior. A requisite for additional terms in the Prony series have also been reported in [49]. We note that the assumption of linear viscoelasticity is violated for the application of larger displacements where geometrical nonlinearities of the structure, damage, and plastic deformation in the unit cell become significant.

\section{Conclusions}

In the presented work, we conducted a complete series of tensile, shear, compression and tensile relaxation experiments on a set of specimens of pantographic structures. The specimens differed in two geometrical characteristics, allowing us to parametrically investigate each of the varied geometrical parameters effect on the resultant behavior of the structure. While the samples in group A were behaving in an expected fashion where smaller pivot length results in larger reaction force, group B showed an aberration. To describe the structure's behavior completely, therefore, we will need refined mathematical models. The data presented here shows the behavior of a unit cell of a larger pantographic structure [27], and therefore can be used to calibrate mathematical models. The solidness of such models can be tested by examining whether unusual behavior (such as what we observed for the sample 
type B2) can be resulted from the model. As geometrical parameters can be changed to cause different behavior in the pantographic structures, the accepted model can then be utilized to find optimal geometrical parameters pertaining to a desired behavior using optimization algorithms.

The set of conducted tests comprise a procedure to characterize pantographic structures and can be used to test similar pantographic structures with different constitutive materials. This allows a comparison to account for the constitutive materials of the structure, and will be beneficial, especially in mathematical modeling of pantographic structures undergoing dynamic loading. To this end, fatigue test along with investigation of the micro-structure of the constituent, both before and after the rupture of the structure, will be studied in future work, which should also take into account material models with the presence of a damage potential as considered in [50-54], because of the greater deformations the pivots undergo. Indeed, we believe that the first natural continuation of our survey in the field of pantographic metamaterial is to introduce the elastoplastic behavior of the constituent material, at least for the pivots. Useful information about their optimal shape could be obtained following the method described in [55-58].

A further investigation, which can also lead to interesting engineering applications, is represented by the modeling of pantographic structures, even at the scale described in this article, immersed in a soft matrix. This type of study can be conducted by means of the definition of appropriate tensors of Eshelby or Green. Some useful results for this purpose are reported in [10, 59-63]. Finally, it would be interesting to study the dynamics in pantographic structures of the same dimensions as those presented in this article. In fact, the propagation of waves in generalized continua [64-66] is a non-trivial problem and can lead to unexpected results. Some preliminary results in the field of pantographic structures can be found in $[67,68]$.

Acknowledgements This research is supported in part by the United States National Science Foundation grant CMMI-1727433.

\section{References}

1. Barchiesi E, Spagnuolo M, Placidi L (2019) Mechanical metamaterials: a state of the art. Math Mech Solids 24(1):212-234

2. Placidi L, Rosi G, Barchiesi E (2019) Analytical solutions of 2dimensional second gradient linear elasticity for continua with cubic-d 4 microstructure. In: New Achievements in Continuum Mechanics and Thermodynamics, Springer, pp 383-401

3. dell'Isola F, Seppecher P, Alibert JJ, Lekszycki T, Grygoruk R, Pawlikowski M, Steigmann D, Giorgio I, Andreaus U, Turco E et al (2018) Pantographic metamaterials: an example of mathematically driven design and of its technological challenges. Contin Mech Thermodyn 1-34. https://doi.org/10. 1007/s00161-018-0689-8
4. Misra A, Lekszycki T, Giorgio I, Ganzosch G, Müller WH, dell'Isola F (2018) Pantographic metamaterials show atypical poynting effect reversal. Mech Res Commun 89:6-10

5. dell'Isola F, Lekszycki T, Pawlikowski M, Grygoruk R, Greco L (2015) Designing a light fabric metamaterial being highly macroscopically tough under directional extension: first experimental evidence. Zeitschrift für angewandte Mathematik und Physik 66:3473-3498

6. Placidi L, Barchiesi E, Turco E, Rizzi NL (2016) A review on 2d models for the description of pantographic fabrics. Zeitschrift für angewandte Mathematik und Physik 67(5):121

7. Barchiesi E, Placidi L (2017) A review on models for the $3 \mathrm{~d}$ statics and 2d dynamics of pantographic fabrics. In: Wave Dynamics and Composite Mechanics for Microstructured Materials and Metamaterials, Springer, pp 239-258

8. Auffray N, dell'Isola F, Eremeyev V, Madeo A, Rosi G (2015) Analytical continuum mechanics à la Hamilton-Piola least action principle for second gradient continua and capillary fluids. Math Mech Solids 20(4):375-417

9. Spagnuolo M, Andreaus U (2019) A targeted review on large deformations of planar elastic beams: extensibility, distributed loads, buckling and post-buckling. Math Mech Solids 24(1):258280

10. Franciosi P, Spagnuolo M, Salman OU (2018) Mean green operators of deformable fiber networks embedded in a compliant matrix and property estimates. Contin Mech Thermodyn 1-32

11. Pietraszkiewicz W, Eremeyev V (2009) On natural strain measures of the non-linear micropolar continuum. Int J Solids Struct 46(3):774-787

12. Altenbach H, Eremeyev V (2009) On the linear theory of micropolar plates. ZAMM-Journal of Applied Mathematics and Mechanics/Zeitschrift für Angewandte Mathematik und Mechanik 89(4):242-256

13. Misra A, Poorsolhjouy P (2015) Granular micromechanics model for damage and plasticity of cementitious materials based upon thermomechanics. Mathematics and Mechanics of Solids $p$ 1081286515576821

14. Misra A, Singh V (2015) Thermomechanics-based nonlinear ratedependent coupled damage-plasticity granular micromechanics model. Contin Mech Thermodyn 27(4-5):787

15. Yang Y, Misra A (2012) Micromechanics based second gradient continuum theory for shear band modeling in cohesive granular materials following damage elasticity. Int $\mathrm{J}$ Solids Struct 49(18):2500-2514

16. Misra A, Poorsolhjouy P (2017) Grain-and macro-scale kinematics for granular micromechanics based small deformation micromorphic continuum model. Mech Res Commun 81:1-6

17. Misra A, Poorsolhjouy P (2015) Identification of higher-order elastic constants for grain assemblies based upon granular micromechanics. Mathematics and Mechanics of Complex Systems 3(3):285-308

18. Misra A, Poorsolhjouy P (2016) Granular micromechanics based micromorphic model predicts frequency band gaps. Contin Mech Thermodyn 28(1-2):215-234

19. Nejadsadeghi N, Placidi L, Romeo M, Misra A (2019) Frequency band gaps in dielectric granular metamaterials modulated by electric field. Mech Res Commun 95:96-103. https://doi.org/10. 1016/j.mechrescom.2019.01.006

20. Lurie SA, Kalamkarov AL, Solyaev YO, Ustenko AD, Volkov AV (2018) Continuum micro-dilatation modeling of auxetic metamaterials. Int J Solids Struct 132:188-200

21. Solyaev Y, Lurie S, Ustenko A (2018) Numerical modeling of a composite auxetic metamaterials using micro-dilatation theory. Contin Mech Thermodyn 1-9. https://doi.org/10.1007/ s00161-018-0730-y 
22. Altenbach H, Eremeyev VA (2008) On the bending of viscoelastic plates made of polymer foams. Acta Mech 204(3):137

23. Altenbach H, Eremeyev V (2008) Analysis of the viscoelastic behavior of plates made of functionally graded materials. ZAMMJournal of Applied Mathematics and Mechanics/Zeitschrift für Angewandte Mathematik und Mechanik 88(5):332-341

24. Alibert JJ, Seppecher P, dell'Isola F (2003) Truss modular beams with deformation energy depending on higher displacement gradients. Math Mech Solids 8(1):51-73

25. Seppecher P, Alibert JJ, dell'Isola F (2011) Linear elastic trusses leading to continua with exotic mechanical interactions. In: Journal of Physics: Conference Series, vol 319. IOP Publishing, p 012018

26. Placidi L, Andreaus U, Giorgio I (2017) Identification of twodimensional pantographic structure via a linear $\mathrm{d} 4$ orthotropic second gradient elastic model. J Eng Math 103:1-21. https://doi. org/10.1007/s10665-016-9856-8

27. dell'Isola F, Giorgio I, Pawlikowski M, Rizzi N (2016) Large deformations of planar extensible beams and pantographic lattices: heuristic homogenization, experimental and numerical examples of equilibrium. In: Proc r Soc a, vol 472. The Royal Society, p 20150790

28. Steigmann D, dell'Isola F (2015) Mechanical response of fabric sheets to three-dimensional bending, twisting, and stretching. Acta Mech Sinica 31(3):373-382

29. Turco E, dell'Isola F, Cazzani A, Rizzi N (2016) Henckytype discrete model for pantographic structures: numerical comparison with second gradient continuum models. Zeitschrift für angewandte Mathematik und Physik 67:85. https://doi.org/10. 1007/s00033-016-0681-8

30. De Angelo M, Barchiesi E, Giorgio I, Abali BE (2019) Numerical identification of constitutive parameters in reduced-order bidimensional models for pantographic structures: application to out-of-plane buckling. Arch Appl Mech 1-26. https://doi.org/10. 1007/s00419-018-01506-9

31. Placidi L, Barchiesi E, Della Corte A (2017) Identification of twodimensional pantographic structures with a linear $\mathrm{d} 4$ orthotropic second gradient elastic model accounting for external bulk double forces. In: Mathematical Modelling in Solid Mechanics, Springer, pp 211-232

32. Turco E, Giorgio I, Misra A, dell'Isola F (2017) King post truss as a motif for internal structure of (meta) material with controlled elastic properties. R Soc Open Sci 4(10): 171153

33. Giorgio I, Rizzi N, Turco E (2017) Continuum moing of pantographic sheets for out-of-plane bifurcation and vibrational analysis. Proc R Soc A 473(2207):20170636

34. Challamel N, Kocsis A, Wang C (2015) Discrete and non-local elastica. Int J Non Linear Mech 77:128-140

35. Turco E, Misra A, Pawlikowski M, dell'Isola F, Hild F (2018) Enhanced piola-hencky discrete models for pantographic sheets with pivots without deformation energy: numerics and experiments. International Journal of Solids and Structures

36. Turco E, Misra A, Sarikaya R, Lekszycki T (2019) Quantitative analysis of deformation mechanisms in pantographic substructures: experiments and modeling. Contin Mech Thermodyn 31:209-223. https://doi.org/10.1007/s00161-018-0678-y

37. Giorgio I (2016) Numerical identification procedure between a micro-cauchy model and a macro-second gradient model for planar pantographic structures Zeitschrift für angewandte Mathematik und Physik 67:95. https://doi.org/10.1007/s00033-0160692-5

38. Battista A, Cardillo C, Del Vescovo D, Rizzi N, Turco E (2015) Frequency shifts induced by large deformations in planar pantographic continua. Nanomechanics Science and Technology: An International Journal 6(2):161-178. https://doi.org/10.1615/Nano mechanicsSciTechnolIntJ
39. Boutin C, Giorgio I, Placidi L et al (2017) Linear pantographic sheets: Asymptotic micro-macro models identification. Mathematics and Mechanics of Complex Systems 5(2):127162

40. Eremeyev VA, dell'Isola F, Boutin C, Steigmann D (2018) Linear pantographic sheets: existence and uniqueness of weak solutions. J Elast 132(2):175-196

41. Rahali Y, Giorgio I, Ganghoffer J, dell'Isola F (2015) Homogenization à la piola produces second gradient continuum models for linear pantographic lattices. Int J Eng Sci 97:148-172

42. Andreaus U, Spagnuolo M, Lekszycki T, Eugster SR (2018) A ritz approach for the static analysis of planar pantographic structures modeled with nonlinear euler-Bernoulli beams. Contin Mech Thermodyn 30:1103. https://doi.org/10.1007/s00161-018-0665-3

43. Turco E, Barcz K, Pawlikowski M, Rizzi N (2016) Non-standard coupled extensional and bending bias tests for planar pantographic lattices. part i: numerical simulations. Zeitschrift für angewandte Mathematik und Physik 67(5):122

44. Turco E, Golaszewski M, Giorgio I, D’Annibale F (2017) Pantographic lattices with non-orthogonal fibres: Experiments and their numerical simulations. Compos Part B Eng 118:1-14

45. Ganzosch G, Hoschke K, Lekszycki T, Giorgio I, Turco E, Müller W (2018) 3d-measurements of 3d-deformations of pantographic structures. Tech Mech 38(3):233-245

46. Ganzosch G, dell'Isola F, Turco E, Lekszycki T, Müller W (2016) Shearing tests applied to pantographic structures. Acta Polytechnica CTU Proceedings 7:1-6

47. Turco E, dell'Isola F, Rizzi N, Grygoruk R, Müller W, Liebold C (2016) Fiber rupture in sheared planar pantographic sheets: Numerical and experimental evidence. Mech Res Commun 76:8690

48. Barchiesi E, dell'Isola F, Laudato M, Placidi L, Seppecher P (2018) A 1d continuum model for beams with pantographic microstructure: Asymptotic micro-macro identification and numerical results. In: Advances in Mechanics of Microstructured Media and Structures, Springer, pp 43-74

49. Rudra R (1987) A curve-fitting program to stress relaxation data. Can Agric Eng 29(2):209

50. Placidi L, Misra A, Barchiesi E (2018) Simulation results for damage with evolving microstructure and growing strain gradient moduli. Contin Mech Thermodyn 1-21. https://doi.org/10.1007/ s00161-018-0693-z

51. Placidi L, Misra A, Barchiesi E (2018) Two-dimensional strain gradient damage modeling: a variational approach. Zeitschrift für angewandte Mathematik und Physik 69(3):56

52. Placidi L, Barchiesi E, Misra A (2018) A strain gradient variational approach to damage: a comparison with damage gradient models and numerical results. Mathematics and Mechanics of Complex Systems 6(2):77-100

53. Placidi L, Barchiesi E (2018) Energy approach to brittle fracture in strain-gradient modelling. Proc R Soc A 474(2210):20170878

54. Spagnuolo M, Barcz K, Pfaff A, dell'Isola F, Franciosi P (2017) Qualitative pivot damage analysis in aluminum printed pantographic sheets: numerics and experiments. Mechanics Research Communications

55. Marmo F, Rosati L (2012) Analytical integration of elasto-plastic uniaxial constitutive laws over arbitrary sections. Int $\mathbf{J}$ Numer Methods Eng 91(9):990-1022

56. D’Annibale F, Rosi G, Luongo A (2015) Linear stability of piezoelectric-controlled discrete mechanical systems under nonconservative positional forces. Meccanica 50(3):825839

57. Marmo F, Rosati L (2013) The fiber-free approach in the evaluation of the tangent stiffness matrix for elastoplastic uniaxial constitutive laws. Int J Numer Methods Eng 94(9):868894 
58. Marmo F, Sessa S, Rosati L (2016) Analytical solution of the cerruti problem under linearly distributed horizontal loads over polygonal domains. J Elast 124(1):27-56

59. Franciosi $\mathrm{P}$ (2018) A decomposition method for obtaining global mean green operators of inclusions patterns. application to parallel infinite beams in at least transversally isotropic media. Int J Solids Struct 147:1-19

60. Trotta S, Marmo F, Rosati L (2017) Evaluation of the eshelby tensor for polygonal inclusions. Compos Part B Eng 115:170-181

61. Franciosi P (2019) Multiple continuity of phases in composite materials: overall property estimates from a laminate system scheme. International Journal of Solids and Structures

62. Franciosi P, Charles Y (2016) Effective property estimates for nphase composites with from all to none co-continuous phases. Int J Solids Struct 96:110-125

63. Franciosi P, Charles Y (2016) Mean green operators and eshelby tensors for hemispherical inclusions and hemisphere interactions in spheres. application to bi-material spherical inclusions in isotropic spaces. Mech Res Commun 75:57-66
64. di Cosmo F, Laudato M, Spagnuolo M (2018) Acoustic metamaterials based on local resonances: homogenization, optimization and applications. In: Generalized models and Non-classical Approaches in Complex Materials 1, Springer, pp 247-274

65. Abbas IA, Abdalla AENN, Alzahrani FS, Spagnuolo M (2016) Wave propagation in a generalized thermoelastic plate using eigenvalue approach. J Therm Stress 39(11):1367-1377

66. Abd-alla AenN, Alshaikh F, Del Vescovo D, Spagnuolo M (2017) Plane waves and eigenfrequency study in a transversely isotropic magneto-thermoelastic medium under the effect of a constant angular velocity. J Therm Stress 40(9):1079-1092

67. Laudato M, Manzari L, Barchiesi E, Di Cosmo F, Göransson P (2018) First experimental observation of the dynamical behavior of a pantographic metamaterial. Mech Res Commun 94:125-127

68. Barchiesi E, Laudato M, Di Cosmo F (2018) Wave dispersion in non-linear pantographic beams. Mech Res Commun 94:128-132

Publisher's Note Springer Nature remains neutral with regard to jurisdictional claims in published maps and institutional affiliations.

\section{Affiliations}

N. Nejadsadeghi ${ }^{1} \cdot$ M. De Angelo ${ }^{2,3} \cdot$ R. Drobnicki ${ }^{4} \cdot$ T. Lekszycki $^{5,6} \cdot$ F. dell'Isola $^{7,8} \cdot$ A. Misra $^{3}$ (D)

N. Nejadsadeghi

nima.nejadsadeghi@ku.edu

1 Mechanical Engineering Department, University of Kansas, 1530 W. 15th Street, Learned Hall, Lawrence, KS 66045-7609, USA

2 Dipartimento di Ingegneria Civile, Edile-Architettura e Ambientale, Università degli Studi dell'Aquila,

Via Giovanni Gronchi 18 - Zona industriale di Pile, 67100, L'Aquila, Italy

3 Civil, Environmental and Architectural Engineering Department, The University of Kansas, 1530 W. 15th Street, Lawrence, KS 66045-7609, USA

4 Dipartimento di Ingegneria e Scienze dell'Informazione e Matematica Università degli Studi dell'Aquila, L'Aquila, Italy

5 Institute of Mechanics and Printing, Warsaw University of Technology, 85 Narbutta Street, 02-524, Warsaw, Poland

6 Department of Experimental Physiology and Pathophysiology, Medical University of Warsaw, 1b Banacha Street, 02-097, Warsaw, Poland

7 Dipartimento di Ingegneria Strutturale e Geotecnica, Università degli Studi di Roma "La Sapienza.", Via Eudossiana 18, 00184, Rome, Italy

8 International Research Center M \& MoCS, Università degli Studi dell'Aquila, Via Giovanni Gronchi 18 - Zona industriale di Pile, 67100, L'Aquila, Italy 